\title{
The Literature of Crowdsourcing in China: Evidence from Weichaishi.com
}

\author{
Bei Wu, Tingting $\mathrm{Wu}$, and Qing Shan $\mathrm{Ng}$
}

\begin{abstract}
As a typical emerging area, crowdsourcing is promoting the contact among the people, organization, society and cooperation. It has been more and more popular that crowdsourcing model is used to solve business problems and take advantage of market opportunities. In this paper, we first review the concept, feature, process of crowdsourcing. Then we distinguish crowdsourcing from outsourcing and point out crowdsourcing's function on companies. Third, we make deep analysis on Weichaishi's crowdsourcing platform in China from the perspective of the operating process, management mechanism and relationship among crowd and outsoucer. At last, we look forward the future study.
\end{abstract}

Index Terms-Crowdsourcing, outsourcing, weichaishi.

\section{INTRODUCTION}

Crowdsourcing is a popular method of obtaining services, ideas, designs and even funds by putting out an "open call" for contributions. Crowdsourcing is a new service concept put forward [1], the critical difference with the outsourcing and crowdsourcing is, the emphasized of outsourcing is highly specialized personnel, the crowdsourcing is express the creative from non-professionals, and more emphasis on the contribution of "amateurs" on the Internet. There is something in common with the Witkey which is put forward in 2005 from China; the meaning of Witkey is the people who created wealth by knowledge and wit, both are fully endorsed the wisdom of human beings from the Internet [2].

Crowdsourcing has been used in multiple domains in order to harness the power and wisdom of the crowd. Perhaps the most well-known example is Wikipedia. It has been also used in business and

Marketing [3], medicine [4], sociology [5], and environmental sciences [6]. Recently, [7], [8] crowdsourcing has been advocated for the domain of information systems analysis and design through the involvement of users in evaluating the software and contributing to update its models and also to evolve and maintain the software.

In this paper, the use of Weichaishi.com (Micro-task) case to illustrate Crowdsourcing in China. Weichaishi.com was founded in January 11, 2011. It is a mobile App that provides business-to-customer tasks a platform to communicate that based on crowdsouring model. Enterprises post the mini-tasks in the platform and mobile users can use phones in the weichashi.com to find those tasks that they are interested in

\footnotetext{
Manuscript received May 25, 2015; revised September 8, 2015.

The authors are with Zhejiang Gongshang University, Zhejiang 310000 , China (e-mail:wubeicoco@foxmail.com, 365663902@qq.com, qshan_zack@qq.com)
}

and capable to accomplish. If the task passes the test, users can gain corresponding cash or integral compensation, and they can withdraw in Alipay. Because this App form is simple, convenient and easy to operate, it is popular very among mobile users. Companies can finish their internal or outsourced tasks at lowest cost.

\section{LITERATURE REVIEW}

\section{A. Relationship between Outsourcing and Crowdsourcing}

Although outsourcing and crowdsourcing have much in common, but some scholars believe that there are some differences between crowdsourcing and outsourcing. XIAO LAN et al. [9] believe outsourcing implementers' main starting point is to reduce costs, save costs and improve efficiency; and crowdsourcing starting point is to focus on the perpetrators of more incumbents to provide creative and open up new creative ways. MA WEI et al. [10] also believe outsourcing is the inevitable result of the specialization of social division of labor, is the product of specialization under the action of economies of scale; Crowdsourcing is benefit from the innovative potential of differentiation, diversification social, is more the behavior of the individual. Outsourcing largely depends on business relationships (financial incentives), while crowdsourcing may have a much more diverse participation motivation, which may lead to multiple incentives [11]. Table I show the outsourcing and crowdsourcing are essentially different in the implementation of the conditions, motivation, performance, risk, incentives and cultural foundations.

Even the outsourcing and crowdsourcing have a lot in common, but in the actual application of thecrowdsourcing model to the cognition of the difference between the two have certain, so as to avoid confusion phenomenon occurring in a use (see Table II, Table III, and Table IV).

\section{B. The Emerging of Crowdsourcing}

The crowdsourcing model at the beginning of the 21st century began to enter into the society of people; there are several reasons for the rise. In this article, through sorting lists a part of the views of scholars. The main reasons for the rise of crowdsourcing are Internet technology, Internet users, the consumer demand, the enterprise development and market competition environment.

\section{Components and Features of Crowdsourcing}

Crowdsourcing is a multidisciplinary concept, Mahmood Hosseini collected papers from various domains of study in which the crowdsourcing was utilized, after studying and analyzing these papers, they identified that crowdsourcing is 
comprised of four parts. These four parts constitute the entire crowdsourcing operation and are as follows:

- The crowd: consists of the people who take part in a crowdsourcing activity.

- The crowdsourcer: the entity (a person, a for-profit organization, a non-profit organization etc.) who seeks the power and wisdom of the crowd for a task at hand.

- The crowdsourcing task: the activity in which the crowd participates.

- The crowdsourcing platform: the system (software or non-software) within which a crowdsourcing task is performed.

TABLE I: THE MAIN DIFFERENCE BETWEEN OUTSOURCING AND CROWDSOURCING

\begin{tabular}{lcc}
\hline Implementation & Outsourcing & Crowdsourcing \\
\hline Time & Start from the 1980s & Start from $21^{\text {st }}$ century \\
Requirement & Is not limited to the Internet & Is limited to the Internet \\
Motivation & Reduce the cost & Problem solving, seek creative \\
Performance & To improve efficiency & Digging creativity \\
Risk & High risk & Low risk \\
Incentives & Financial incentives & Multiple incentives \\
Cultural & Collaborative & Participatory
\end{tabular}

Source: According to the relevant papers, arranged by the authors

TABLE II: THE REASON FOR THE RISE OF CROWDSOURCING

\begin{tabular}{|c|c|c|}
\hline The Reason & Explain & Mentioned In \\
\hline Internet technology & $\begin{array}{l}\text { The development of information technology makes people from different places can be instant } \\
\text { communication, business consulting between service providers and customers no longer need to face to face, } \\
\text { could be more quick and convenient access to new information needed. }\end{array}$ & {$[10],[12]$} \\
\hline $\begin{array}{l}\text { Internet users } \\
\text { numbers }\end{array}$ & $\begin{array}{l}\text { Intelligent terminal and mobile Internet users rapid growth and expansion of the scale, all the packages for the } \\
\text { network and the rapid development of mobile crowdsourcing innovation model provides the high quality of } \\
\text { foundation platform and implementation conditions. }\end{array}$ & [13] \\
\hline $\begin{array}{l}\text { The consumer } \\
\text { demand }\end{array}$ & $\begin{array}{l}\text { In the pursuit of personalized era, consumers do not content to just be a simple product recipients, and to look } \\
\text { through to join the innovation of product design, to have distinctive personalized products. }\end{array}$ & {$[12]$} \\
\hline $\begin{array}{l}\text { The enterprise } \\
\text { development }\end{array}$ & $\begin{array}{l}\text { The crowdsourcing model in addition to reduce costs and improve product quality also can better reduce the } \\
\text { distance between the brand and users; increase the user for the loyalty of the brand. }\end{array}$ & {$[14],[15]$} \\
\hline $\begin{array}{l}\text { Market competition } \\
\text { environment }\end{array}$ & $\begin{array}{l}\text { Competition in the external environment and consumer demand diversification and differentiation for } \\
\text { crowdsourcing market conditions. }\end{array}$ & $\begin{array}{l}{[12],[16],} \\
{[17]}\end{array}$ \\
\hline
\end{tabular}

Source: According to the relevant papers, arranged by the authors

TABLE III: The FEATURES OF THE Four PARTS OF CROWDSOURCING

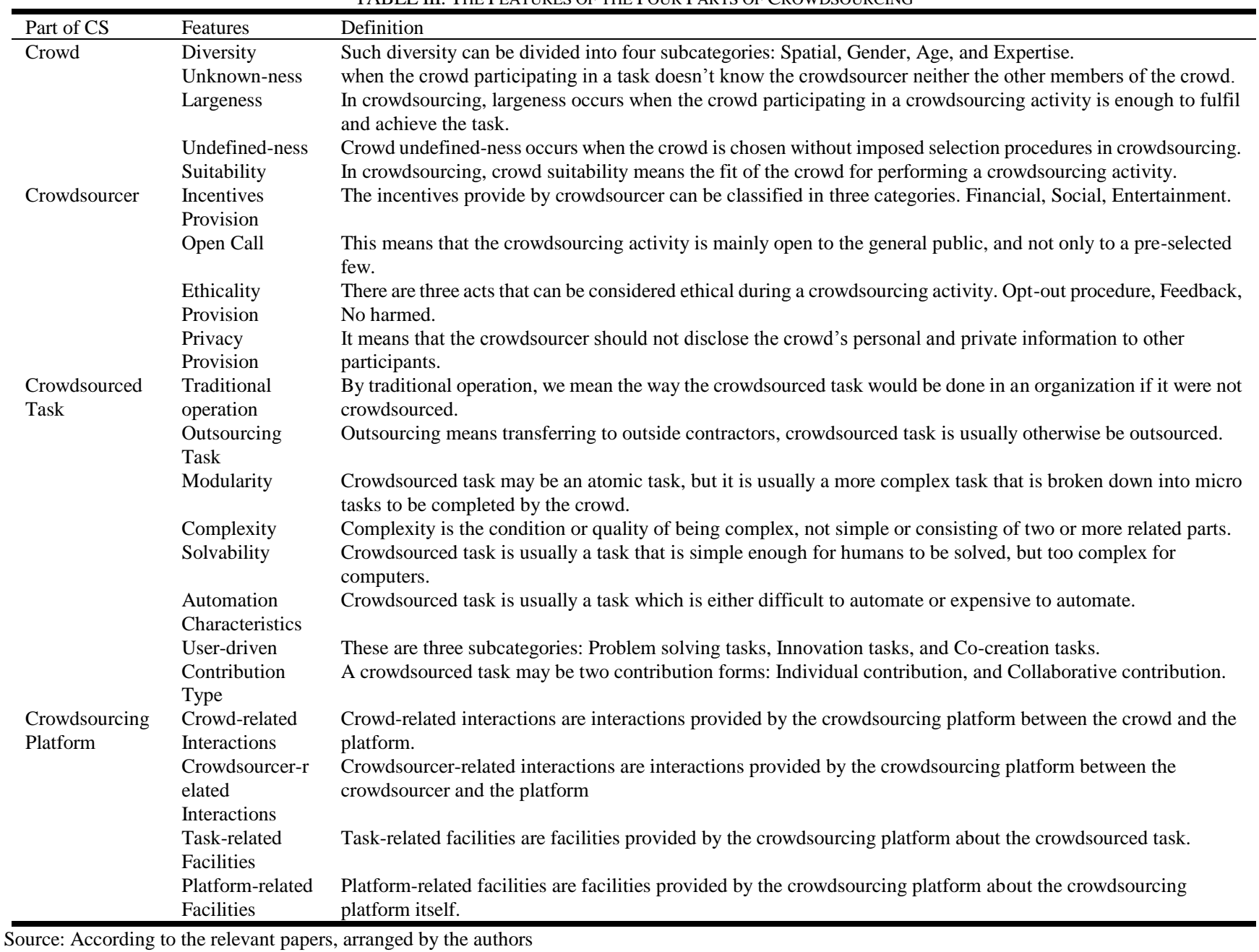

Source: According to the relevant papers, arranged by the authors 
To fully understand the concept of crowdsourcing, many scholars have discussed and studied from various aspects. Performed a systematic mapping study and selected 113 papers, after evaluating these papers and identifying the four parts of crowdsourcing, they tried to identify these features and subsections by performing a content analysis on the definitions. The main characteristics of four parts are as follows:

\section{Operation Process and Mode of Crowdsourcing}

Crowdsourcing is a web based business pattern, which make best use of the individuals on the internet, through open call, and finally get innovative solutions [18]. Mode of operation crowdsourcing model is mainly based on the platform from the Internet, the main factors involved in the platform has the crowd, the crowdsourcer, crowdsourced task, and the crowdsourcing platform [19]. The general process of crowdsourcing is as follows:

- Crowdsourcer propose tasks, and make it known to the public through internet or other media, at the same time, make clear the requirement of the solution and reward to the winners;

- The public submit potential solutions;

- The public or investigate, or evaluate the solutions, and choose the best one;

- Crowdsourcer determines the best solution, and reward the winner;

- Crowdsourcer gets and owns the best solution.

Although all the operation of crowdsourcing platform is almost the same, in fact there are some essential differences exist between the platforms. WEI [16] put the crowdsourcing platform into four patterns by the content of the public contributions, Dell's "Ideas to Remit" of collective intelligence model, television user generated content of public create model, news recommended of public voting model, and microfinance of public financing model. Rouse [20], Schenk and Guittard [21] characterize the functions of crowdsourcing applications by the nature and granularity of the task into high task granularity, middle task granularity, and low task granularity.

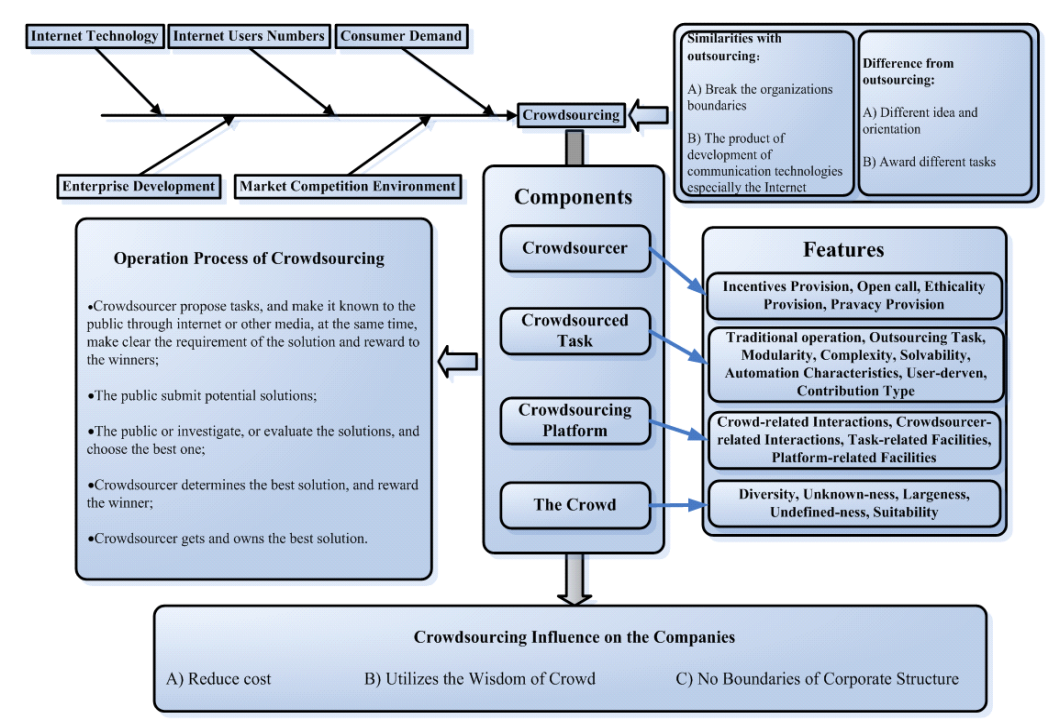

Fig. 1. Basic introduction of crowdsourcing.

In this paper, the case close to collective intelligence model and low task granularity, it means the platform usually deals with some routine tasks, such as data collection, rating, and translation of simple texts. On the basis of the above characteristics, we can think of this case platform operation mode is the micro-task markets which is anyone can post tasks to be completed and specify prices paid for completing them.

According to the study of Kittur et al. Micro-task markets such as WeiChaiShi.com and AMT are promising platforms for conducting a variety of user study tasks, ranging from surveys to rapid prototyping to quantitative performance measures.

\section{E. Crowdsourcing Influence on the Company's}

As people are so through intelligent terminals and mobile terminals to use the Internet more and more familiar with, the crowdsourcing also with the help of the power of the Internet has changed the relationship between the company and the consumer, use the crowdsourcing model also allows company to benefit from it. Crowdsourcing the impact on the company has the following several aspects:

1) Reduce costs: the innovation of information technology broke the barrier isolation professionals and amateurs, many amateurs and part-timers find can play to work platform, while the labor force is not free, but compared with the traditional way of employees, its cost isn't worth mentioning [22].

2) Utilized the wisdom of crowd: Swarm intelligence is sometimes beyond individual intelligence and puts forward a proposition that open innovation, the innovation of the traditional enterprises rely mainly on the research and development department of the enterprise itself, and now companies relying on employees, suppliers, or university public wisdom to carry out research and development has become more important [23].

3) No boundaries of corporate structure: Internet-based crowdsourcing break the constraints of time and space, the participants from around the world, in favors of the corporate structure without boundaries [10]. In the open 
innovation model, companies are able to penetrate the border [24]. Innovative ideas not only from internal R\&D department, and may also come from outside the enterprise.

Based on the theoretical analysis about the emergence, concept, process, characteristic, and features of crowdsourcing, and influence on the companies, we represent the relationship between crowdsourcing and these theories, as shown in Fig. 1. It shows the overview of crowdsourcing.

\section{CASE STUdY}

As the pioneer of Crowdsourcing in China, Weichaishi.com make users to extend field workforce at their fingertips. Users across the country can be quickly mobilized to help the business to complete various tasks at a much cost-effective and efficient way. They advocate is "WCS APP, it's EASY, it's FUN, and it PAYS!"

With its list/map mode switching view function, mobile users can find opportunities to make money easily. After filling in the user information, they can filter tasks intelligently, and choose their own task. They can also add some tasks to wish list in case of missing them. Once tasks pass the test, users can get corresponding payment that transfer directly into their accounts. The finance status and payment are clear in users' accounts. The platform also set different levels for tasks, the more advanced the task is, the more payment users will get.

At present, the superstar function commercial check just meets the need of enterprises and brands on labor crowdsourcing, such as retail inspection, monitoring activities and advertising. And the other three functions - data collection, research \&survey and experience \&trials, perfect the platform in the aspects of commercial data collection, market research, product marketing. With the help of this platform, enterprises can break the limitation of geography, reduce the cost of task execution efficiently and fill the gap of human resources quickly.

\section{A. Services}

Commercial Check: Mobile users through all kinds of "monitoring" and "the inspector" enterprise or mall activities reflect the data information in time, using the data to help enterprise to see the status of the terminal market, and to help enterprises improve implementation quality and real market demand, enhance the sale and brand awareness.

Data Collection: Weichaishi.com registered users through the use of mobile phones has various functions, to collect various text and multimedia related to enterprise information and automatically upload, enterprise through the review, screening information, thus provides the need of important data basis for the enterprise, forming huge amount of valuable information assets.

Research \& Survey: On micro errand, mobile users through the use of some professional research tools and methods, to help enterprises to further understand the demand of target customers, and create a large user "big data" database, enterprises take advantage of these data for research and development, production and sales.

Experience \& Trials: Mobile users by watching, listening, trial, to participate in the enterprise in weichaishi.com posted on verities of activities, the target audience directly using the enterprise products, is the user has sufficient imaginary space and personal feeling, to maximize the user participation and share interest and feedback information obtained from the user experience, to find the product defects and to improve in time, enhance the consumers to the brand identity. Special products and services, as shown in Fig. 2 and Fig. 3.

TABLE IV: THE SERVICES OF WEICHAISHI.COM

\begin{tabular}{ll}
\hline $\begin{array}{l}\text { Pattern } \\
\text { Classification }\end{array}$ & Task Type \\
\hline Experience \& Trials & $\begin{array}{l}\text { To store experience, Participate In Activities, Product Trial ,Financial products, Game experience, Hot to snap up, Shopping cash } \\
\text { back, Crowdsourcing sales, Online interactive, NISSAN JUKE, Registered experience, App Experience }\end{array}$ \\
$\begin{array}{l}\text { Data Collection } \\
\text { Commercial Check }\end{array}$ & $\begin{array}{l}\text { Information gathering, Addresses to collect } \\
\text { Stores to check, Outdoor check }\end{array}$ \\
\hline
\end{tabular}

Source: According to the weichaishi.com applications

The current version of the weichaishi.com can support iphone 6 and android dual system and get rid of the limitations of the domestic most APP cannot be applied to the iphone system. As one of the few to make money of B2C mobile terminal based crowdsourcing platform also has its own crowdsourcing Chinese characteristics. Weichaishi.com errands with millions of users across the country, distribution in one, two, three line cities across China, task to complete channel sinks to the lowest layer users. weichaishi.com is paid by results, The enterprise can be released task at though the platform where have millions of users in real time around the China. Users accept the task by using GPS real-time location tracking, Understand the progress of the completion of the task. Audited up to standard, the final payment, which point to the enterprise and there is no risk.

\section{B. From the Fragments of Time to Explore Business Opportunities}

With the popularity of mobile phones, mobile internet users are increasing. These mobile phone users in addition to study, work, exercise, rest, etc. There are have a lot of fragmented time, most people mostly use these fragments of time in the brush micro-blogging, Wechat, etc. Today, social networking elements to increase penetration into all mobile applications, user-friendly to express their views, users are more willing to create some content. The job is using micro-fragments of time to earn extra money on the public platform for enterprises. For example, JCDecaux map the country to collect their building and POI information on its own human, material and financial resources. 


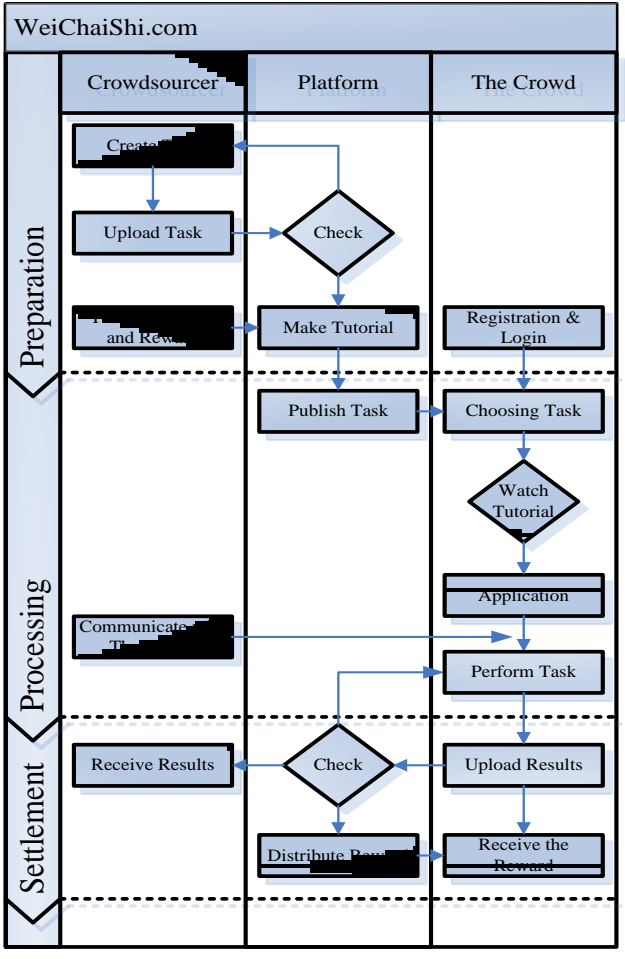

Fig. 2. Relationship among weichaishi.com, enterprises and users.

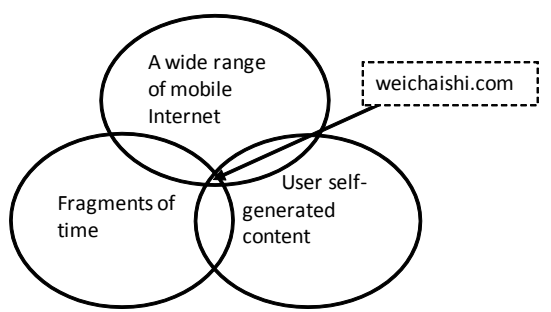

Fig. 3. Basic introduction of weichaishi.com.

\section{Do Platforms: Differential Move B Side in Advance}

Many of crowdsourcing platforms are $\mathrm{C} 2 \mathrm{C}$ model Or Although B2C model, but are the first to emphasize is to set up the back-end $\mathrm{C}$, again attracting the front of the $\mathrm{C}$ or $\mathrm{B}$, while the micro-job is a lot of work to do first attract a large number of $\mathrm{B}$ end, primarily micro errand pioneers who are have a lot of work and entrepreneurial experiences. For example Bu Jun, Coca-Cola China had to work for 10 years, as China business consultant, responsible for Coke distribution network and market access strategy formulation and implementation. It need time to understand what competitors are doing, and what they do have their own business, how to perform capacity and so on. Understanding these business pain points, with questions about cooperation with B easily achieve the target effect.

\section{The Classification of the C-Terminal User Management}

Currently over one million registered users as much micro errands, distribution of the country, covering all provinces, municipalities and towns. So many users, micro job by building trust system. Registered users need to use real identity information, so we can see micro errand user's age, gender, education, etc., and thus suitable for the task assigned to them. According to the type of user, it will give them a different entrance to do their own tasks. In addition, there is a core team. They have some preferential policies, more assignments and different types of tasks. Some processes, such as enterprise business operations and key task, will be done by them. Therefore, the security aspects of business will be quite perfect.

\section{E. To Prevent Users from Cheating Fraud}

In terms of user cheating fraud, does not have a micro errand started relatively sound system. Some users do not have to complete the task, but it created a lot of extra work to make the platform test users do things, this will result in increased operating costs. Later, through the use of micro errand get real user information, mechanism establishment of a comprehensive technical and credit operations, which can be done to prevent cheating fraud behavior of users.

\section{CONCLUSION AND FUtURE WORK}

We have taken weichaishi as our example to show that crowdsourcing can be applied to wide variety of problems, which raises numerous interesting technical and social challenges. Given the success of current crowdsourcing model, we expect that emerging field will grow rapidly in China. At present, crowdsourcing is an initial stage in Chinato solve simple and single problems, such as investigation, monitoring, and simple logo design. In the future, we will make further study on industries about some basic problems such as how to use crowdsourcing model, how to get the big data combined with the crowdsourcing model and so on.

\section{ACKNOWLEDGMENT}

It is a project supported by National Science Fund (No.71472169) and the normal project of Hangzhou philosophy and social science (No. A14GL05). This research is supported by the Contemporary Business and Trade Research Center of Zhejiang Gongshang University which is the Key Research Institute of Social Sciences and Humanities Ministry of Education.

\section{REFERENCES}

[1] J. Howe. "The rise of crowdsourcing," Wired Magazine, vol. 14, no. 6, pp. 1-5, 2006.

[2] L. Feng, "The speech at the world Witkey conference by the creator of Witkey theory," Journalism Research Herald, vol. 3, pp. 12-14, 2011.

[3] P. Whitla, "Crowdsourcing and its application in marketing activities," Contemporary Management Research, vol. 5, no. 1, 2009.

[4] B. Yu, M. Willis, P. Sun, and J. Wang, "Crowdsourcing participatory evaluation of medical pictograms using Amazon mechanical Turk," Journal of Medical Internet Research, vol. 15, no. 6, p. 108, 2013.

[5] M. N. Wexler, "Reconfiguring the sociology of the crowd: exploring crowdsourcing," International Journal of Sociology and Social Policy, vol. 31, no. 1-2, 2011.

[6] P. Fraternali, A. Castelletti, R. Soncini-Sessa, C. Vaca Ruiz, and A. E. Rizzoli, "Putting humans in the loop: Social computing for Water Resources Management," Environmental Modelling \& Software, vol. 37, pp. 68-77, 2012.

[7] R. Ali, C. Solis, I. Omoronyia, M. Salehie, and B. Nuseibeh. "Social adaptation: When software gives users a voice," ENASE, pp. 28-30, 2012.

[8] D. Pagano and W. Maalej, "User feedback in the appstore: An empirical study," in Proc. $21^{\text {st }}$ IEEE International Requirements Engineering Conference, 2013, pp. 125-134.

[9] L. Xiao and C. C. Gao, "'Crowdsourcing' to change the business model innovation," Shanghai Economic Research, vol. 3, 2010.

[10] W. Ma, L. Fang, and J. Z. Tu, "Business model from outsourcing to Crowdsourcing Innovation and Enlightenment," Commercial Times, vol. 1, pp. 13-14, 2008. 
[11] Y. X. Zhao and Q. H. Zhu, "Evaluation on crowdsourcing research: Current status and future direction," Information Systems Frontiers, vol. 16, no. 3, pp. 417-434, 2014.

[12] W. H. Liu and Z. H. Ruan, "Crowdsourcing: Allows consumers to participate in innovation," Operation and Management, vol. 8.

[13] Y. Zhang, Y. Sun, and H. L. Yan, "Crowdsourcing review of," Economic Vision, vol. 6, 2014.

[14] V. Hippel "People don't need a profit motive to innovate," Harvard Business Review, pp. 36-37, 2011.

[15] Y. Xie, "Pepsi: Using social networking 'crowdsourcing' community marketing," Successful Marketing, vol. 4, pp. 26-27, 2010.

[16] S. C. Wei, "Crowdsourced ideas as well as our enterprise crowdsourcing business model design," Technology \& Management Research, vol. 1, pp. 36-39, 2010.

[17] L. B. Zhang, F. P. Zhong, and H. Tu. "Crowdsourcing questions research review," Science and Technology Progress and Countermeasures, vol. 6, pp. 154-160, 2012.

[18] J. Howe. (2010). Crowdsourcing: A definition. crowdsourcing: Why the Power of the crowd is driving the future of business. [Online] Available:

http://crowdsourcing.typepad.com/cs/2006/06/crowdsourcing_a.html

[19] L. Zhang and H. J. Zhang, "Research of crowdsourcing model based on case study," presented at 2011 8th International Conference on Service Systems and Service Management, 2011.

[20] A. Rouse, "A preliminary taxonomy of crowdsourcing," in Proc. ACIS, 2010, p. 76.

[21] E. Schenk and C. Guittard, "Crowdsourcing: What can be outsourced to the crowd, and why?" 2009.
[22] A. Kittur, E. H. Chi, and B. Suh, "Crowdsourcing user studies with mechanical Turk," in Proc. the SIGCHI Conference on Human Factors in Computing Systems, 2008, pp. 453-456.

[23] S. James, "The wisdom of crowds: Why the many are smarter than the few and how collective wisdom shapes business, economies, societies, and nations," New York Doubleday, vol. 54, no. 1-2, pp. 68-69, 2004.

[24] W. C. Henry, Open Innovation, the New Imperative for Creating and Profit from Technology, Harvard Business School Press, 2003.

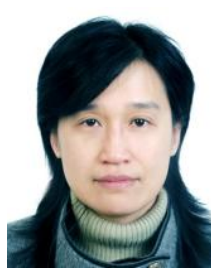

Bei Wu was born in Hunan province, China in February 1973. From 2004 to 2010, she graduated from Zhejiang University. From 2004 to date, she worked in Zhejiang Gongshang University. She is a $\mathrm{PhD}$, a professor of management science. Her research direction is crowdsourcing, R\&D outsourcing and technology innovation. She had published several academic papers in China first-class journal and hosted 2 National Science Fund.

Tingting Wu was born in Anhui province, China in April 1990. From 2009 to 2013 Tingting Wu graduated from Wanxi University. From 2014 to date, Tingting Wu enrolled in master's degree in logistics engineering in Zhejiang Gongshang University.

Ng Qing Shan was born in Malaysia in December 1990. Ng Qing Shan got the degree course in business management from Zhejiang Gongshang University. At this stage is studying the master in management science and engineering in Zhejiang Gongshang University and focus on virtual community of knowledge transfer performance. 